\title{
Mi viaje de este veranen
}

En realidad, yo ni siquiera quería estudiar alemán.

En serio, yo creía que el capítulo de los idiomas estaba cerrado para mí y que ya no sería nunca una de esas personas que saben alemán.

A pesar de ello, resulta que mi director de tesis concibe este simple y ameno idioma como fundamental para mi formación y como donde manda patrón no manda marinero, más valía ponerse manos a la obra.

Así que, preguntando aquí y allá, un amigo traductor me habló de aquel viaje que una vez hizo a una ciudad alemana llamada Passau. De hecho, le gustó tanto, que repitió al verano siguiente.

Parecían buenos antecedentes y a aquellas alturas del curso, tampoco sería ya posible encontrar otra cosa para el verano, así que (teniendo en cuenta además lo escandalosamente barato del viaje...) me embarqué.

El caso es que, por diferentes casualidades, no conseguí ir a ninguna de las reuniones previas al viaje y tuve que verme aquí o allá con la con la organizadora para terminar pagando en el aeropuerto el día de la salida.

Es lo malo que tienen estos viajes, que te apuntas, pagas $y \ldots$ oye, acabas metido en un avión con un montón de gente desconocida y sin saber muy bien a lo que vas (cosa que se había explicado con todo lujo de detalles en las reuniones). Pero, por otro lado, también es lo bueno que tienen estos viajes: empieza la aventura.

Doce horas, prácticamente doce horas es el tiempo que separa el verme pasar el control policial del aeropuerto de Málaga conociendo sólo a la organizadora de haberla visto un par de veces en el Deutsch Konsulat, de verme en mi litera de la 133 hablando y riendo con dos de los amigos con los que pasaría más de un rato inolvidable, zu viel Raten inolvidablen.

En Passau ocurre una cosa muy extraña, el tiempo al convertirse en die Zeit adquiere extrañas dimensiones. En cuestión
JOSÉ BECERRA

Universidad de Málaga

de horas tienes 23 nuevos amigos, aprendes a pronunciar Haus der Jugend, Volkshochschule, rauchen verboten... y todo ello habiendo dado en Málaga un curso de tan sólo veinte horas, ¿quién da más?.

En cuestión de días tienes un montón de salidas nocturnas a la marcha de Passau que se convierten en excursiones por el bosque a la luz de las linternas, litros y más litros de cerveza, fruta bañada en chocolate, Viena, Munich, Praga, la frontera con Austria a pie, siempre a pie, hasta descubrir incluso la existencia de ciertos músculos en tus piernas que no sabías ni que existían. Des-

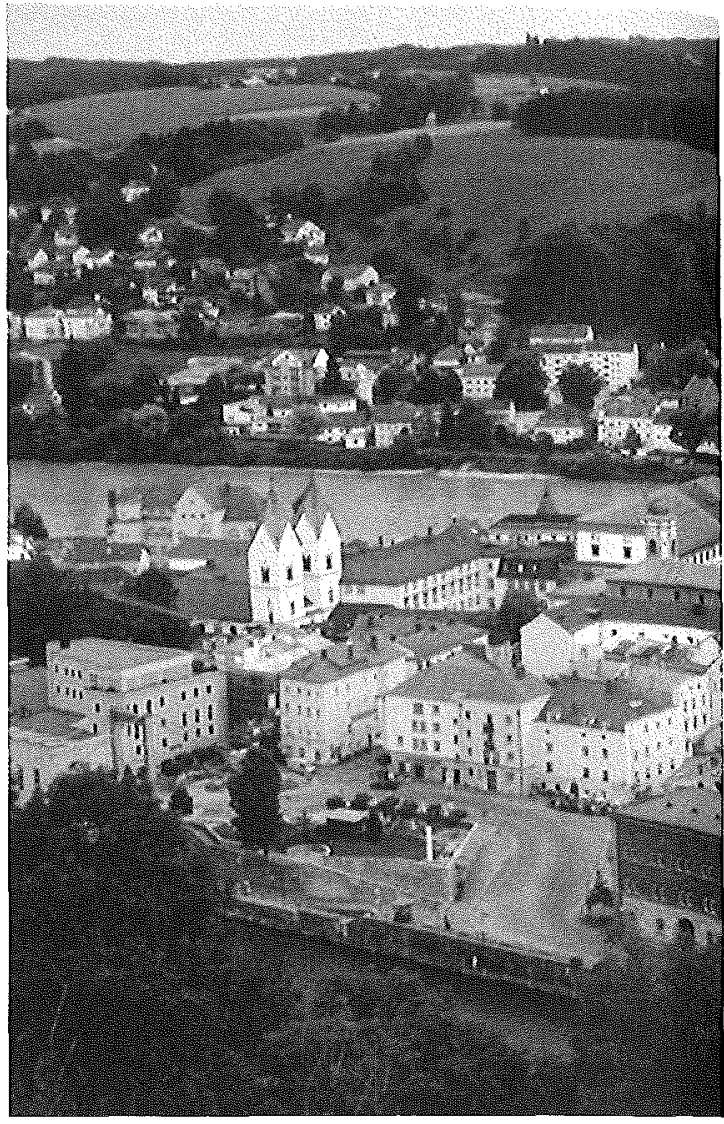
cubres, en el comedor de la escuela, que para la sorprendentemente buena cocina alemana hay vida más allá de las salchichas. Vuelves a la infancia de la mano de aquel estrés por hacer los Hausaufgabe y también al visitar la piscina municipal (pseudo parque acuático) donde... en fin... como niños.

La Catedial (por favor que no la encalen), das Rathaus, ríos y más ríos, grandes para pasear en barco o estudiar en sus orillas y pequeños para recorrerlos con el agua templada por las rodillas...

Passau es una ciudad con encanto, tiene ese toque anaranjado al anochecer, que hace de las calles de algunas ciudades, una imagen de postal. Allí la vida es tranquila, fluye como el ritmo de sus ríos, de sus bicicletas, ágil, constante y sin estridencias. Rodeada de un verde imponente, cualquier solitario viajero (como el que en ocasiones me ha tocado ser) descubre en ella un muy agradable lugar para fondear durante algún tiempo.

Pero, por suerte para mí, esta vez la soledad no ha sido precisamente una característica de mi tiempo allí. Desde compartir siete tartas en Viena, cantar en el micró- fono del autobús a un grupo de Rusas muy de Siberia, a comer bocadillos y más bocadillos en común, bailar en el metro de $\mathrm{Mu}$ nich, organizar una genial fiesta de cumpleaños, sortear sapos en la subida a casa, bailar sevillanas para los pasauenses, las interminables conversaciones nocturnas, jugar a las cartas en Praga... hmmm, Praga...

Debo confesar que en este viaje no tenía puestas muchas expectativas, simplemente no me apetecía pasar otro verano fuera de casa ni estudiar una lengua que todo el mundo sabe que es complicada. Tal vez sea por eso mi sorpresa haya sido mayor que en los demás al descubrir un grupo de gente simplemente tan «apañá», con tantas ganas de trabajar y, al mismo tiempo de pasarlo bien, ipero si hasta ya sé hablar algo en alemán!.

En fin, una estancia inolvidable, en la que he aprendido, he disfrutado muchísolvidaré.

Sólo dos cosas más: a los que fuisteis conmigo gracias por ayudarme a pasarlo tan bien y a los que pensáis ir, ique nunca un alemán os pregunte la hora! mo y he encontrado gente a la que nunca 